\title{
Relationship Between Structure and Glass Transition Temperature in Low-silica Calcium Aluminosilicate Glasses: the Origin of the Anomaly at Low Silica Content
}

\author{
Laurent Cormier ${ }^{\dagger}$ \\ Laboratoire de Minéralogie-Cristallographie, Universités Paris 6 et 7 et Institut de physique du globe de Paris, CNRS \\ UMR 7590, 75252 Paris cedex 05, France \\ Daniel R. Neuville \\ Physique des Minéraux et des Magmas, Institut de physique du globe de Paris, CNRS UMR 7047, \\ 75252 Paris cedex 05, France \\ Georges Calas* \\ Laboratoire de Minéralogie-Cristallographie, Universités Paris 6 et 7 et Institut de physique du globe de Paris, CNRS \\ UMR 7590, 75252 Paris cedex 05, France
}

\begin{abstract}
The anomalous behavior of the glass transition temperature $\left(T_{\mathrm{g}}\right)$ in low silica calcium aluminosilicate glasses has been related to the structural modifications observed by neutron and $\mathrm{X}$-ray diffraction. The diffraction data indicate that $\mathrm{Al}$ and $\mathrm{Si}$ are in tetrahedral sites and that $\mathrm{Ca}$ atoms are in distorted octahedral sites. By subtracting the correlation functions for glasses at constant $\mathrm{SiO}_{2}$ or constant $\mathrm{Al}_{2} \mathrm{O}_{3}$ content, we have shown that $\mathrm{Si}$ and $\mathrm{Al}$ atoms are introduced in a different way within the glass structure. $\mathrm{Si}$ is present in various $\mathbf{Q}^{n}$ sites, while $\mathrm{Al}$ resides in $\mathbf{Q}^{3}$ and $\mathrm{Q}^{4}$ sites for glasses with high $\mathrm{CaO}$ content and enters fully polymerized $\mathrm{Q}^{4}$ sites with increasing $\mathrm{SiO}_{2}$ or $\mathrm{Al}_{2} \mathrm{O}_{3}$ content. The higher proportion of $\mathrm{Al}$ in $\mathrm{Q}^{3}$ positions at high $\mathrm{CaO}$ content yields a depolymerization of the network. The lower connectivity will contribute to a decrease of the viscosity, which may be at the origin of the decrease of $T_{\mathrm{g}}$ for glasses at low silica content.
\end{abstract}

\section{Introduction}

L ow silica glasses may be synthesized in the $\mathrm{CaO}-\mathrm{Al}_{2} \mathrm{O}_{3}-\mathrm{SiO}_{2}$ system, a unique property among silicate glasses. ${ }^{1-3}$ In a narrow range of composition $(70-60 \mathrm{~mol} \% \mathrm{CaO})$, the calcium aluminate binary glasses can be produced by conventional melt quenching techniques. The addition of a small amount of $\mathrm{SiO}_{2}$ allows a broadening of the glass forming ability over a larger calcium concentration range and a lowering of the liquidus temperature. ${ }^{3,4}$ The introduction of silica strongly affects some physical properties and thus the structure of these glasses. ${ }^{3,4}$ For instance, the glass transition temperature, $T_{\mathrm{g}}$, presents a maximum at $10-20 \mathrm{~mol}^{\circ} \mathrm{SiO}_{2}$ along joins with a constant $\mathrm{CaO} / \mathrm{Al}_{2} \mathrm{O}_{3}$ ratios. Several models have been proposed to explain this behavior:

(a) the so-called " $T_{\mathrm{g}}$ model" suggests that, at low silica content, non-bridging oxygens (NBOs) are preferentially located on the $\mathrm{SiO}_{4}$ tetrahedra. ${ }^{4}$ The dominant aluminate network contains less NBOs and is thus more connected, which increases $T_{\mathrm{g}}$. With further addition of silica, $\mathrm{SiO}_{4}$ tetrahedra become part of the

H. Anderson-contributing editor

Manuscript No. 187214. Received January 10, 2002; approved March 2, 2005

${ }^{*}$ Member, American Ceramic Society.

Author to whom correspondence should be addressed. e-mail: cormier@lmcp.jussieu.fr aluminate network and the NBOs are randomly distributed between $\mathrm{Si}$ and $\mathrm{Al}$.

(b) Another model proposes that the addition of $\mathrm{SiO}_{2}$ to Ca-aluminate glasses tends to increase $T_{\mathrm{g}}$ due to greater average polymerization and larger average bond strength. With further increase in the $\mathrm{SiO}_{2}$ content, the decrease in $T_{\mathrm{g}}$ results from an increasing free volume that arises from structural changes similar to those existing between crystalline aluminates and gehlenite structures. ${ }^{5}$

(c) The presence of excess oxygen has been reported with the observation of superoxide radicals by electron paramagnetic resonance on unirradiated samples. ${ }^{5-8}$ These $\mathrm{O}_{2}^{-}$ions indicate that peroxy linkages $(-\mathrm{O}-\mathrm{O}-)$, peroxide ions coordinated to $\mathrm{Ca}^{2+}$ ions or dissolved molecular oxygen, $\mathrm{O}_{2}$, could be present in significant amounts, and it was proposed that their presence affects the network polymerization and thus $T_{\mathrm{g}}$.

Structural studies of these glasses have mainly focused on the aluminosilicate network using ${ }^{29} \mathrm{Si}$ and ${ }^{27} \mathrm{Al}$ MAS-NMR,,${ }^{9-13}$ X-ray absorption spectroscopy (XAS), ${ }^{13,14}$ Raman and infrared reflectance spectrocopies, ${ }^{10,15,16}$ and X-ray and neuron diffraction. ${ }^{17-20}$ All these investigations reveal the presence of a tetrahedral aluminosilicate network in which the charge compensation for the negatively charged $\left(\mathrm{AlO}_{4}\right)^{-}$tetrahedra is provided by $\mathrm{Ca}^{2+}$ ions. ${ }^{21}$ For glasses with $\mathrm{R}=\mathrm{CaO} / \mathrm{Al}_{2} \mathrm{O}_{3}>1$, Ca atoms present in excess for charge compensation have a modifying role with the formation of NBOs. Neutron diffraction measurements were recently carried out on calcium aluminosilicate glasses, where the local environment around $\mathrm{Ca}$ was shown to be distorted and close to an octahedral site. ${ }^{20}$ However, to our knowledge, there are no extensive diffraction studies on glasses containing low silica content.

This paper reports neutron and X-ray diffraction measurements on low-silica calcium aluminosilicate glasses. The glass transition temperature of these glasses was derived from viscosity measurement. ${ }^{22}$ The coupling of the two diffraction techniques provides insight into the environment at the local and medium range around all the constituting elements and information on the medium range structure of the aluminosilicate network. By taking the difference between the correlation functions for glasses at constant $\mathrm{SiO}_{2}$ or constant $\mathrm{Al}_{2} \mathrm{O}_{3}$ content, we show the possibility to obtain additional structural information on the respective role of $\mathrm{Al}$ and $\mathrm{Si}$ in the polymerization of the aluminosilicate network and its evolution with the addition of $\mathrm{SiO}_{2}$. In $\mathrm{CaO}$-rich glasses, $\mathrm{Al}$ resides in depolymerized units, which are incorporated into more polymerized units with 


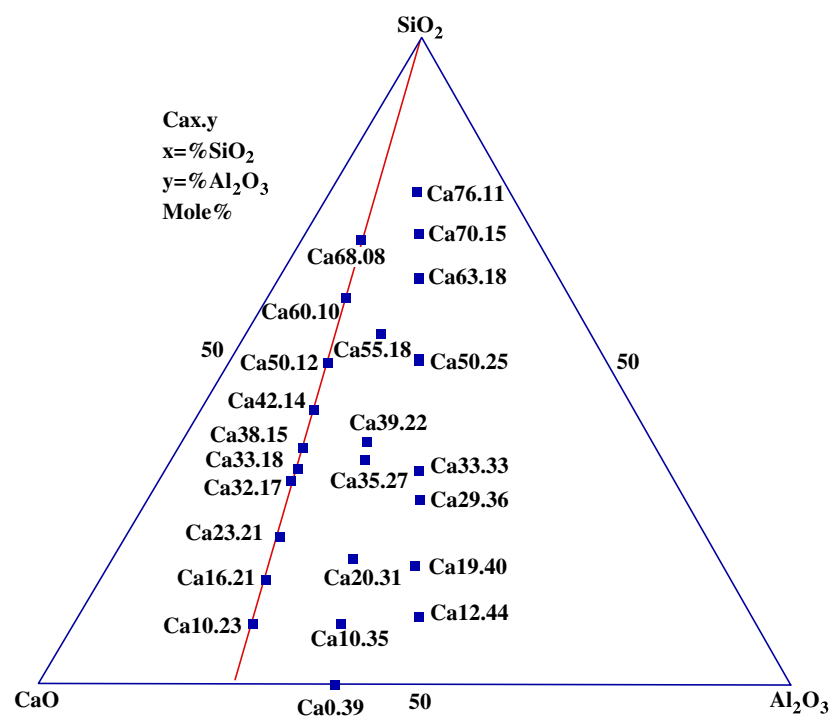

Fig. 1. Glass compositions studied in the $\mathrm{SiO}_{2}-\mathrm{Al}_{2} \mathrm{O}_{3}-\mathrm{CaO}$ ternary system along the joins $R=\mathrm{CaO} / \mathrm{Al}_{2} \mathrm{O}_{3}=1,1.57$ and 3 .

the addition of $\mathrm{SiO}_{2}$ or $\mathrm{Al}_{2} \mathrm{O}_{3}$, while $\mathrm{SiO}_{4}$ tetrahedra are preferentially localized in a distribution of depolymerized environments. These structural results allow the establishment of a relationship between the glass structure and the glass transition temperature.

\section{Experimental Procedure}

Calcium aluminosilicate glasses belonging to the $\mathrm{SiO}_{2}-\mathrm{Al}_{2} \mathrm{O}_{3}-$ $\mathrm{CaO}$ ternary system were selected along the joins $\mathrm{R}=\mathrm{CaO}$ $\mathrm{Al}_{2} \mathrm{O}_{3}=1,1.57,3$ with silica content between 0 and $76 \mathrm{~mol} \%$ (Fig. 1). Samples were prepared from reagent grade $\mathrm{CaCO}_{3}$, $\mathrm{Al}_{2} \mathrm{O}_{3}$, and $\mathrm{SiO}_{2}$. The appropriate quantities of powders were melted at $1900 \mathrm{~K}$ during $4 \mathrm{~h}$ in a platinum crucible and then quenched by immersion of the bottom of the crucible in water. ${ }^{23}$

Table I. Nominal Glass Composition of the Glasses in the $\mathrm{SiO}_{2}-\mathrm{Al}_{2} \mathrm{O}_{3}-\mathrm{CaO}$ Ternary System

\begin{tabular}{lcccc}
\hline Sample $^{\dagger}$ & $\mathrm{SiO}_{2}(\mathrm{~mol} \%)$ & $\mathrm{Al}_{2} \mathrm{O}_{3}(\mathrm{~mol} \%)$ & $\mathrm{CaO}(\mathrm{mol} \%)$ & $\mathrm{R}=\mathrm{CaO} / \mathrm{Al}_{2} \mathrm{O}_{3}$ \\
\hline $\mathrm{Ca} 10.23$ & 10.00 & 22.50 & 67.50 & 3 \\
$\mathrm{Ca} 16.21$ & 16.57 & 20.86 & 62.57 & 3 \\
$\mathrm{Ca} 23.21$ & 23.50 & 21.00 & 55.50 & 3 \\
$\mathrm{Ca} 32.17$ & 31.91 & 17.02 & 51.07 & 3 \\
$\mathrm{Ca} 33.18$ & 33.18 & 17.63 & 49.13 & 3 \\
$\mathrm{Ca} 38.15$ & 37.93 & 15.51 & 45.56 & 3 \\
$\mathrm{Ca} 42.14$ & 42.86 & 14.28 & 42.86 & 3 \\
$\mathrm{Ca} 50.12$ & 51.43 & 12.14 & 36.43 & 3 \\
$\mathrm{Ca} 60.10$ & 60.00 & 10.00 & 30.00 & 3 \\
$\mathrm{Ca} 68.08$ & 68.30 & 8.71 & 22.97 & 3 \\
$\mathrm{Ca} 0.39$ & 0.00 & 39.00 & 61.00 & 1.57 \\
$\mathrm{Ca} 10.35$ & 10.00 & 35.00 & 55.00 & 1.57 \\
$\mathrm{Ca} 20.31$ & 20.00 & 31.00 & 49.00 & 1.57 \\
$\mathrm{Ca} 35.27$ & 35.00 & 27.00 & 38.00 & 1.57 \\
$\mathrm{Ca} 39.22$ & 39.25 & 22.25 & 38.50 & 1.57 \\
$\mathrm{Ca} 55.18$ & 55.00 & 17.50 & 27.50 & 1.57 \\
$\mathrm{Ca} 12.44$ & 11.82 & 44.10 & 44.10 & 1 \\
$\mathrm{Ca} 19.40$ & 18.99 & 40.51 & 40.51 & 1 \\
$\mathrm{Ca} 29.36$ & 29.00 & 36.00 & 35.00 & 1 \\
$\mathrm{Ca} 33.33$ & 33.33 & 33.33 & 33.33 & 1 \\
$\mathrm{Ca} 50.25$ & 50.00 & 25.00 & 25.00 & 1 \\
$\mathrm{Ca} 63.18$ & 63.30 & 18.35 & 18.35 & 1 \\
$\mathrm{Ca} 70.15$ & 70.00 & 15.00 & 15.00 & 1 \\
$\mathrm{Ca} 76.11$ & 76.50 & 11.75 & 11.75 & 1 \\
\hline
\end{tabular}

${ }^{\dagger} \mathrm{Cax} . y$, with $x$ the molar percentage of $\mathrm{SiO}_{2}, y$ the molar percentage of $\mathrm{Al}_{2} \mathrm{O}_{3}$ and $(1-x-y)$ the molar percentage of $\mathrm{CaO}$.
This process was repeated four times to ensure glass homogeneity. With this procedure the quench rate is estimated to be $\sim 20^{\circ} \mathrm{C} / \mathrm{s}$. No thermal annealing of the glasses was carried out. The samples have a slightly yellow coloration due to small dissolution of $\mathrm{Pt}^{4+}$. It was recently shown that the solubility of $\mathrm{Pt}$ decreases with the addition of silica. ${ }^{23}$ The composition of the samples are listed in Table I. We use the notation Cax.y, where $x$ and $y$ refer to the molar percent of $\mathrm{SiO}_{2}$ and $\mathrm{Al}_{2} \mathrm{O}_{3}$, respectively, and $1-x-y$ is the $\mathrm{CaO}$ molar content.

The $T_{\mathrm{g}} \mathrm{s}$ were determined by viscosity measurements performed with a creep apparatus and a rotatory viscometer that give values between 1 and $10^{14} \mathrm{P}^{22,24}$ The $T_{\mathrm{g}}$ values, plotted in Fig. 2, correspond to $10^{13} \mathrm{P}$ on a relaxed viscosity curve. The glass transition temperature is a dynamic phenomenon that does not only depend on the chemical composition but also on the speed of heating/cooling rate. However, for each temperature of measurement, the viscosity was obtained on relaxed liquids and thus the $T_{\mathrm{g}}$ values are independent of the thermal history of the glass. A second set of $T_{\mathrm{g}}$ was taken from Higby et al. ${ }^{4}$ who determined the glass transition temperatures from DTA measurements. It is well known that there is a difference of a few degrees between the glass transition temperature obtained from viscosity measurement and from DTA. Some glasses were studied by these two ways, and the difference corresponded to $20^{\circ}$. We subtract $20^{\circ}$ at the glass transition temperature determined from DTA to have compatible data sets in Fig. 1.

Wide angle X-ray scattering (WAXS) experiments were performed on a diffractometer equipped with $M o K \alpha$ radiation and a bent graphite monochromator (Philips, Eindhoven, The Netherlands, PW1729). The intensity measurements were carried out by the $\theta / 2 \theta$ step scanning method and in the angular range of $0.5^{\circ}<$ $2 \theta<140^{\circ}$, which corresponds to a $Q$-range $0.8<Q<16.6 \AA^{-1}$ ( $Q=4 \pi \sin \theta / \lambda$ is the magnitude of the scattering vector, $2 \theta$ is the scattering angle, and $\lambda$ is the radiation wavelength). The total counts accumulated at each measured point were not less than 10000 . The X-ray source was operated at a current of $35 \mathrm{~mA}$ and accelerating voltage of $50 \mathrm{kV}$. Standard treatment was carried out to correct and normalize the experimental diffraction data and to obtain the total structure factor, $S(Q) .^{25}$

Neutron total diffraction experiments were carried out on the SANDALS diffractometer at the ISIS spallation neutron source (Rutherford Appleton Laboratory, U.K.). A wide range of scattering vectors $\left(0.2 \AA^{-1}<Q<50 \AA^{-1}\right)$ can be obtained. The samples were crushed and loaded in a thin-walled vanadium container. Diffracted intensities were recorded at room temperature for the samples in the container, the empty container, and a vanadium rod used for absolute normalization. The data were corrected for background and container scattering, absorption, multiple scattering, and inelasticity effects using the ATLAS suite of programs. ${ }^{26}$

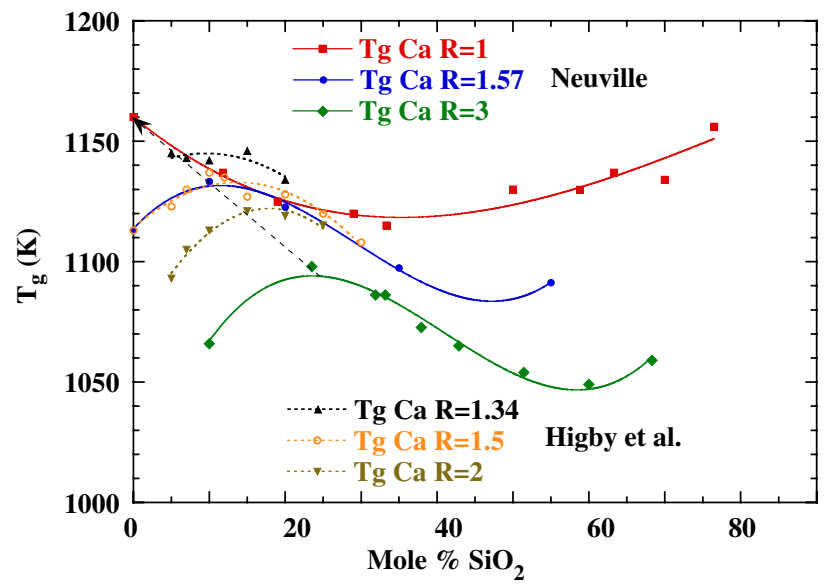

Fig. 2. Glass transition temperatures as a function of $\mathrm{SiO}_{2}$ content in the ternary $\mathrm{CaO}-\mathrm{Al}_{2} \mathrm{O}_{3}-\mathrm{SiO}_{2}$ system. (Data from Highby et al. ${ }^{4}$ for joins $R=2,1.34$, and 1.57.) Lines are guide for the eye only. 
The neutron and X-ray structure factors were Fourier transformed to give the total correlation functions, $G(r)$.

$$
\begin{aligned}
& G(r)=2 / \pi \int_{0}^{Q_{\max }} Q[S(Q)-1] \exp \left(-\alpha Q^{2}\right) \sin (Q r) \mathrm{d} Q \\
& G(r)=4 \pi r \rho_{0}(g(r)-1)
\end{aligned}
$$

where $g(r)$ describes the local density fluctuations around unity and $\rho_{0}$ is the average number density. A modification function, $\exp \left(-\alpha Q^{2}\right)$, is used to down-weight the high-angle data, with a damping factor $\alpha=0.005$.

The total correlation function is a weighted sum of the partial pair distribution functions (PPDFs). In multicomponent systems, the structural information that can be extracted from the data is limited by the overlapping of the various PPDFs. For example, in the aluminosilicate glasses, the $\mathrm{Al}-\mathrm{T}$ and $\mathrm{Al}-\mathrm{O}$ PPDFs have maxima near those of the $\mathrm{Si}-\mathrm{T}$ and $\mathrm{Si}-\mathrm{O}$ PPDFs, with $\mathrm{T}=\mathrm{Si}$ or Al. The determination of each of these partial pair distribution functions is required to obtain information on the polymerization of the glass network. By taking the difference between the correlation functions for glasses at constant $\mathrm{SiO}_{2}$ or $\mathrm{Al}_{2} \mathrm{O}_{3}$ content, it is possible to subtract some contributions and, thus, to obtain more structural information from the data. We make the reasonable hypotheses (i) that, at constant $\mathrm{SiO}_{2}$ content, the addition of about $10 \mathrm{~mol} \% \mathrm{Al}_{2} \mathrm{O}_{3}$ has little influence on the local geometry of the $\mathrm{SiO}_{4}$ tetrahedra and (ii) that modifications at longer distances will be negligible. In consequence, there are few changes for the $\mathrm{Si}-\mathrm{O}$ and $\mathrm{Si}-\mathrm{Si}$ PPDFs between different glasses with the same $\mathrm{SiO}_{2}$ content. The difference taken between the correlation functions should thus eliminate most of the $\mathrm{Si}-\mathrm{O}$ and $\mathrm{Si}-\mathrm{Si}$ contributions and allows a more precise determination of the $\mathrm{Al}-\mathrm{T}$ and $\mathrm{Al}-\mathrm{O}$ contributions, though no quantitative analysis can be considered in these differential correlation functions.

\section{Results}

\section{(1) Glass Transition Temperatures}

Figure 2 shows the glass transition temperatures obtained from viscosity measurements $(\log \eta=13 \mathrm{P})$ as a function of $\mathrm{SiO}_{2}$ content for the three joins $\mathrm{SiO}_{2}-R$, with $R=\mathrm{CaO} / \mathrm{Al}_{2} \mathrm{O}_{3}$ taken between 1 and 3 . For all joins, we observe an important decrease in the glass transition temperatures with decreasing $\mathrm{SiO}_{2}$ content from 76 to $30 \mathrm{~mol} \%$, which results from the depolymerization of the three-dimensional silica network. The $T_{\mathrm{g}}$ varies by about 400 $\mathrm{K}$ between pure $\mathrm{SiO}_{2}\left(T_{\mathrm{g}} \sim 1500 \mathrm{~K}\right)$ and the center of the ternary system $\left(T_{\mathrm{g}}=1115 \mathrm{~K}\right.$ for $\left.\mathrm{Ca} 33.33\right)$. For the join $R=1$ and for glasses with less than $30 \mathrm{~mol} \% \mathrm{SiO}_{2}$, we observe a continuous increase in the $T_{\mathrm{g}}$ with decreasing silica content. The extrapolation of the experimental $T_{\mathrm{g}}$ values for this join yields for the $\mathrm{CaAl}_{2} \mathrm{O}_{4}$ composition a $T_{\mathrm{g}}$ of $1160 \pm 2 \mathrm{~K}$. The same value was found by DSC measurements on a sample synthesized by aerodynamic levitation and laser heating. ${ }^{25}$ This value is also in fairly good agreement with an extrapolation of the maximum of $T_{\mathrm{g}}$ along the different joins (dashed line in Fig. 2). The increase in $T_{\mathrm{g}}$ as the $\mathrm{SiO}_{2}$ content decreases $\left(\mathrm{SiO}_{2}<30 \mathrm{~mol} \%\right)$ indicates that aluminium in tetrahedral coordination ${ }^{20}$ plays a role similar to the silicium in the $\mathrm{SiO}_{2}$-rich part, i.e., a network forming role in a three-dimensional network.

A striking behavior is observed for the two other joins $R=1.57$ and 3 . The $T_{\mathrm{g}}$ values present a maximum at 10 and $20 \mathrm{~mol} \%$ of silica, respectively. These augmentations are more important for the join $R=3$ than for the join $R=1.57$. These results are in good agreement with those of Higby et al. ${ }^{4}$ obtained from DTA measurements. The explanation for this behavior will be given below in relation to the structural modifications.

\section{(2) Total Diffraction Functions}

The total X-ray and neutron structure factors, $S(Q)$, are shown in Fig. 3. The first peak in the neutron data (Fig. 3(a)) is shifted

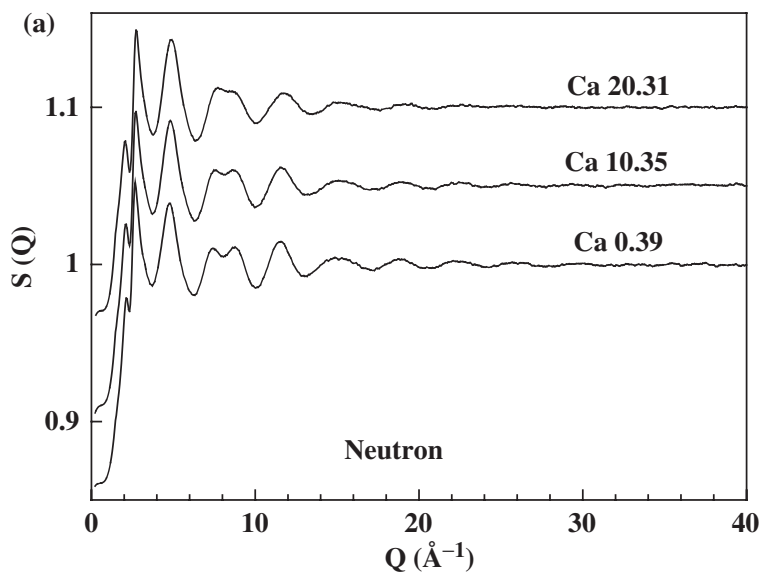

(b)

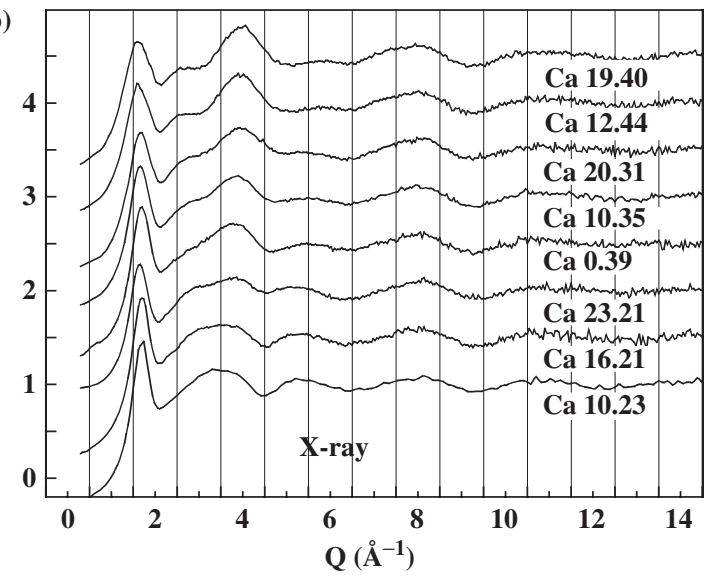

Fig. 3. (a) Neutron structure factors for the $61 \mathrm{CaO} \cdot 39 \mathrm{Al}_{2} \mathrm{O}_{3}(\mathrm{Ca} 0.39)$, $55 \mathrm{CaO} \cdot 35 \mathrm{Al}_{2} \mathrm{O}_{3} 10 \cdot \mathrm{SiO}_{2}(\mathrm{Ca} 10.35)$, and $49 \mathrm{CaO} \cdot 31 \mathrm{Al}_{2} \mathrm{O}_{3} \cdot 20 \mathrm{SiO}_{2}$ (Ca20.31) samples. (b) X-ray structure factors for the Cax.y samples, where $x, y$, and $1-x-y$ are the molar percent of $\mathrm{SiO}_{2}, \mathrm{Al}_{2} \mathrm{O}_{3}$, and $\mathrm{CaO}$, respectively. Some curves are displaced vertically for clarity.

from $2.14 \pm 0.01 \AA^{-1}$ to $2.06 \pm 0.01 \AA^{-1}$ as the $\mathrm{SiO}_{2}$ content increases from 0 up to $20 \%$ and the width remains almost constant. In the X-ray data (Fig. 3(b)), a first peak appears between $2.08 \pm 0.02 \AA^{-1}$ (for glasses with $R=1$ ) and $2.24 \pm 0.02 \AA^{-1}$ (for glasses with $R=3$ ).

The neutron correlation functions, $G(r)$, are presented in Fig. 4(a) and Gaussian fits up to 3.2 A are shown in Fig. 4(b). Structural oscillations are clearly visible up to about $15 \AA$, which indicate an important degree of medium range order in these glasses. The first peak corresponds to the $\mathrm{Al}-\mathrm{O}$ contribution only, in the $\mathrm{Ca} 0.39$ sample and to both $\mathrm{Al}-\mathrm{O}$ and $\mathrm{Si}-\mathrm{O}$ contributions in the Ca10.35 and Ca20.31 samples. The Al-O peak in $\mathrm{Ca} 0.39$ was fitted using one Gaussian function while a second Gaussian contribution was added to fit the $\mathrm{Si}-\mathrm{O}$ pair in the other two glasses. The fitting parameters are listed in Table II. With the addition of $\mathrm{CaO}$, the $\mathrm{Ca}-\mathrm{O}$ contribution near $2.4 \AA$ is enhanced. This peak is partially overlapped by the $\mathrm{O}-\mathrm{O}$ contribution near $2.8 \AA$, which is shifted to lower $r$-values and broadened with the addition of $\mathrm{SiO}_{2}$. Indeed, the $\mathrm{O}-\mathrm{O}$ bond lengths in $\mathrm{SiO}_{4}$ tetrahedra are about $0.2 \AA$ A shorter, typically, than those in $\mathrm{AlO}_{4}$ tetrahedra (Table II).

Structural modifications can be observed between 3 and $5 \AA$ (Fig. 5), in the $X$ ray correlation function, though they have less defined structures at high $r$-values and a lower resolution at low $r$-values, due to the limited $Q$-range accessible in our data $\left(0.8 \AA^{-1}<Q<15 \AA^{-1}\right)$. The weights of the different pairs differ in X-ray and neutron diffraction data and, thereby, X-ray diffraction data give complementary information on the structure. In particular, the pairs involving $\mathrm{Ca}$ and $\mathrm{Si} / \mathrm{Al}$ are more heavily weighted in the X-ray data compared to the neutron ones where the pairs involving $\mathrm{O}$ dominate the signal. This explains why the 

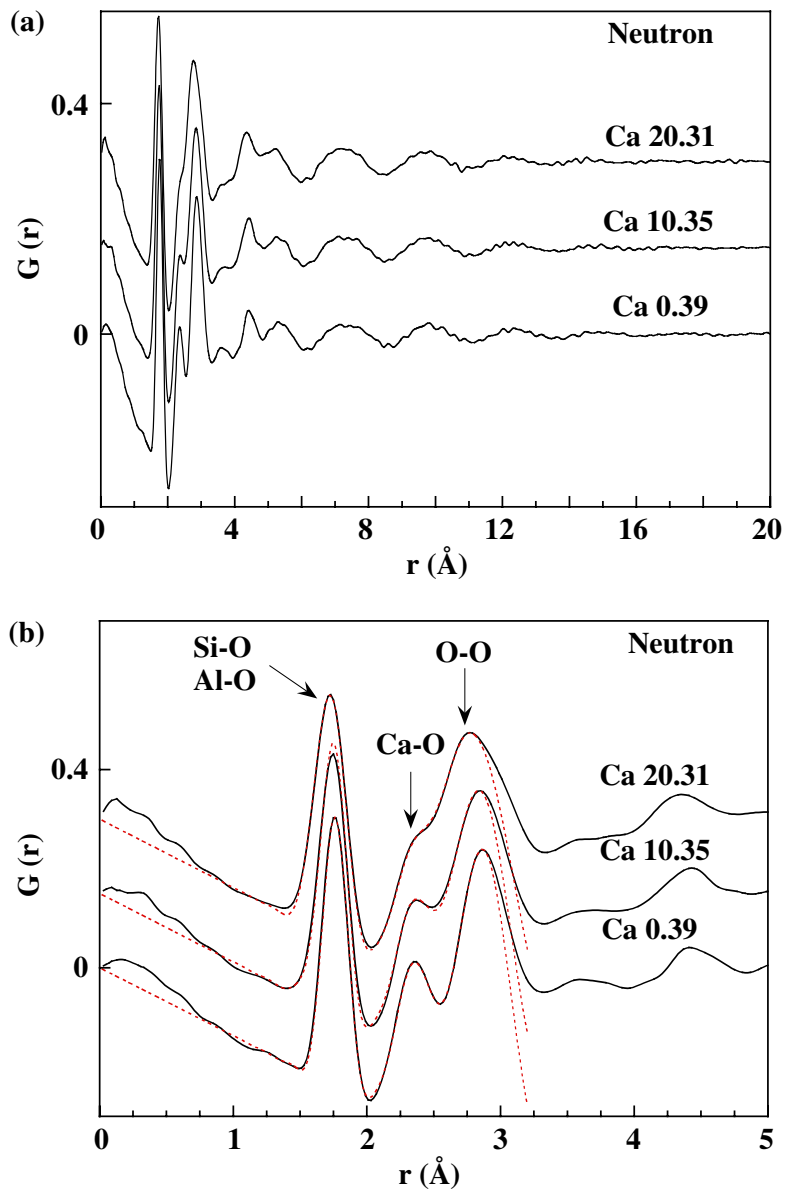

Fig. 4. (a) Neutron correlation function for the $\mathrm{Ca} 0.39$, Ca10.35, and Ca20.31 samples, which show the structural oscillations above 10 A. (b) Comparison between the experimental neutron correlation functions (solid curves) and the Gaussian fits (dashed curves) up to $3.2 \AA$ with the Gaussian parameters listed in Table II. Some curves are displaced vertically for clarity.

$\mathrm{Ca}-\mathrm{O}$ pair is more apparent in the X-ray data though, again, an exact determination of its area is difficult due to the proximity of the $\mathrm{O}-\mathrm{O}$ contribution. Upon the addition of $\mathrm{CaO}$, contributions near 3.4 and $3.8 \AA$ increase in intensity and may be assigned to $\mathrm{Ca}-\mathrm{Ca}$ and $\mathrm{Ca}-\mathrm{T}$ pairs, where $\mathrm{T}$ stands for $\mathrm{Si}$ or $\mathrm{Al}_{.}{ }^{18}$ For glasses with low $\mathrm{CaO}$ content, the $\mathrm{T}-\mathrm{T}$ pair near $3.15 \AA$ and the $\mathrm{T}$ second nearest oxygen (T-O2) pair at about $4.4 \AA$ are clearly visible.

Table II. Gaussian Fit Parameters for the Various Pairs Up to $3 \mathrm{~A}$

\begin{tabular}{clllll}
\hline & & & & \multicolumn{2}{c}{$\mathrm{O}-\mathrm{O}$} \\
\cline { 5 - 6 } Sample & $\mathrm{Si}-\mathrm{O}$ & $\mathrm{Al}-\mathrm{O}$ & $\mathrm{Ca}-\mathrm{O}$ & $\left(\mathrm{SiO}_{4}\right)$ & $\left(\mathrm{AlO}_{4}\right)$ \\
\hline $\mathrm{CaO} .39$ & & & & & \\
$r^{\dagger}(\AA)$ & & 1.765 & 2.36 & & 2.885 \\
$N^{\ddagger}$ & & 4.1 & 4.7 & & 4.83 \\
$\sigma^{\ddagger}(\AA)$ & & 0.06 & 0.12 & & 0.19 \\
$\mathrm{Ca}^{\ddagger} 0.35$ & & & & & \\
$r^{\dagger}(\AA)$ & 1.620 & 1.762 & 2.35 & 2.65 & 2.89 \\
$N^{\ddagger}$ & 4.1 & 4.1 & 4.5 & 0.65 & 4.33 \\
$\sigma^{\S}(\AA)$ & 0.05 & 0.052 & 0.12 & 0.17 & 0.20 \\
$\mathrm{Ca} 20.31$ & & & & & \\
$r^{\dagger}(\AA)$ & 1.625 & 1.763 & 2.35 & 2.65 & 2.90 \\
$N^{\ddagger}$ & 4.0 & 4.1 & 4.5 & 0.97 & 4.05 \\
$\sigma^{\S}(\AA)$ & 0.05 & 0.065 & 0.12 & 0.14 & 0.22 \\
\hline
\end{tabular}

${ }_{\dagger}^{\dagger}$ Interatomic distance. ${ }^{\ddagger}$ Coordination number. ${ }^{\S}$ Standard deviation.
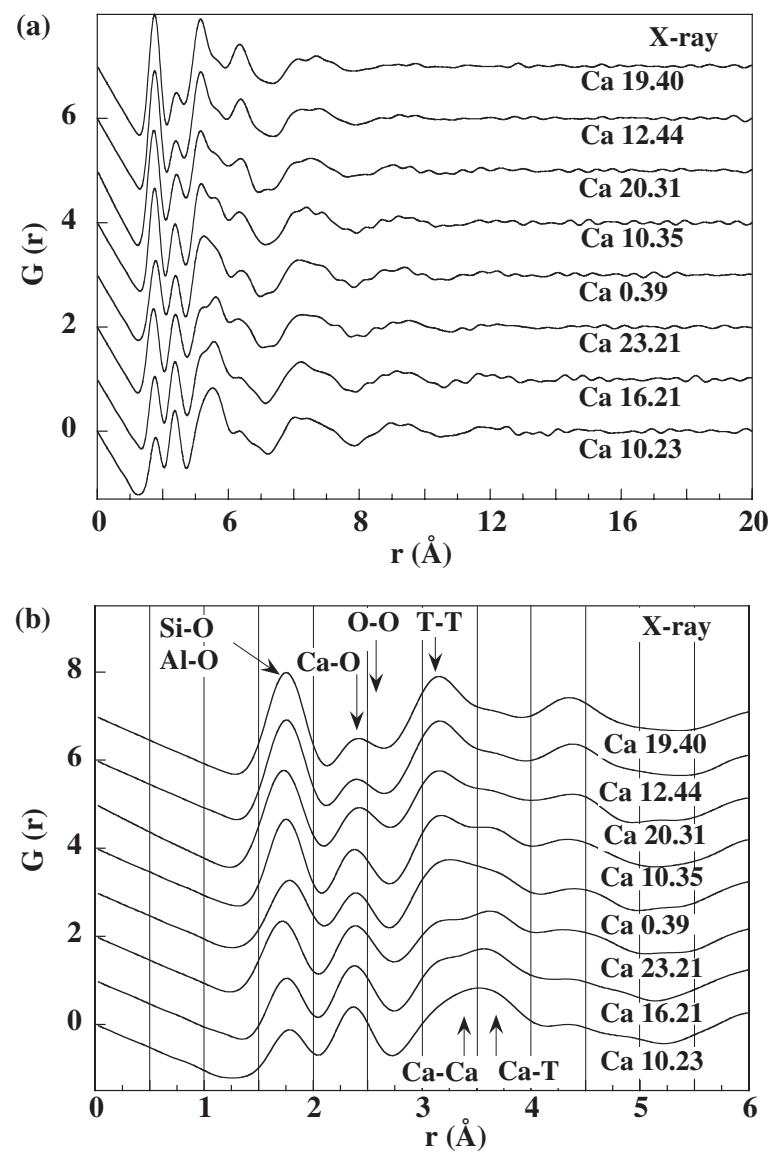

Fig.5. (a) X-ray correlation functions for the Cax.y glasses, which shows the structural oscillations above $10 \mathrm{~A}$. (b) Details of the X-ray correlation functions between 0 and $6 \AA$. Some curves are displaced vertically for clarity.

\section{(3) Difference Diffraction Functions}

Figure 6 shows the neutron correlation difference functions taken between $\mathrm{Ca} 10.35$ and $\mathrm{Ca} 0.39$ (bottom, plain curve) and $\mathrm{Ca} 20.31$ and $\mathrm{Ca0} .39$ (bottom, dashed curve). With the addition of silica, the contributions due to the $\mathrm{SiO}_{4}$ tetrahedra are visible at $1.6 \AA$ ( $\mathrm{Si}-\mathrm{O}$ pairs) and $2.6 \AA$ (O-O pairs). Second nearest neighbor silicon-oxygen distances, $\mathrm{Si}-\mathrm{O} 2$, can be seen at $4.2 \AA$.

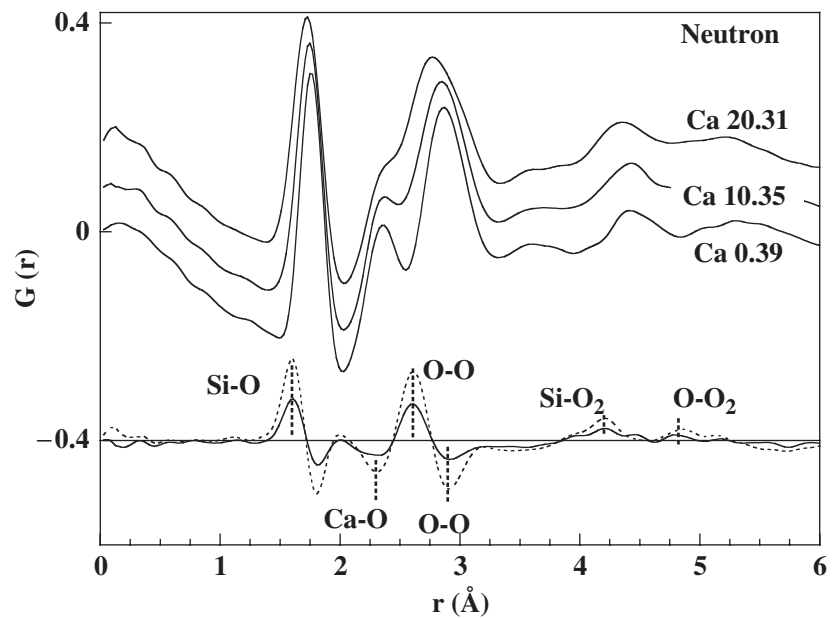

Fig. 6. Neutron correlation function for the $\mathrm{Ca} 0.39$, Ca10.35, and Ca20.31 samples (three top solid curves) and neutron difference correlation functions (two bottom curves) between the $\mathrm{Ca} 0.39$ and $\mathrm{Ca} 10.35$ samples (plain curve) and the Ca0.39 and Ca20.31 samples (dashed curve). Some curves are displaced vertically for clarity. 
A positive feature at $4.8 \AA$ can be assigned to $\mathrm{O}-\mathrm{O} 2$ and $\mathrm{Si}-\mathrm{T} 2$ pairs that correspond to the second nearest neighbor $\mathrm{O}-\mathrm{O}$ and $\mathrm{Si}-(\mathrm{Si} / \mathrm{Al})$, respectively. ${ }^{17,27}$ The $\mathrm{Si}-\mathrm{O} 2$ pair at $4.2 \AA$ is present even at low silica content since this contribution appears for the Ca10.35 glass and increases in the same proportion between the Ca10.35 and Ca20.31 glasses. This contribution is characteristic of $\mathrm{Si}$ atoms linked with an oxygen belonging to another tetrahedra and it is thus the trademark of $\mathrm{Si}$ atoms linked with another tetrahedra, either $\mathrm{SiO}_{4}$ or $\mathrm{AlO}_{4}$. The decrease in the $\mathrm{Ca}-\mathrm{O}$ pair is due to the lesser content of $\mathrm{CaO}$ as silica is added.
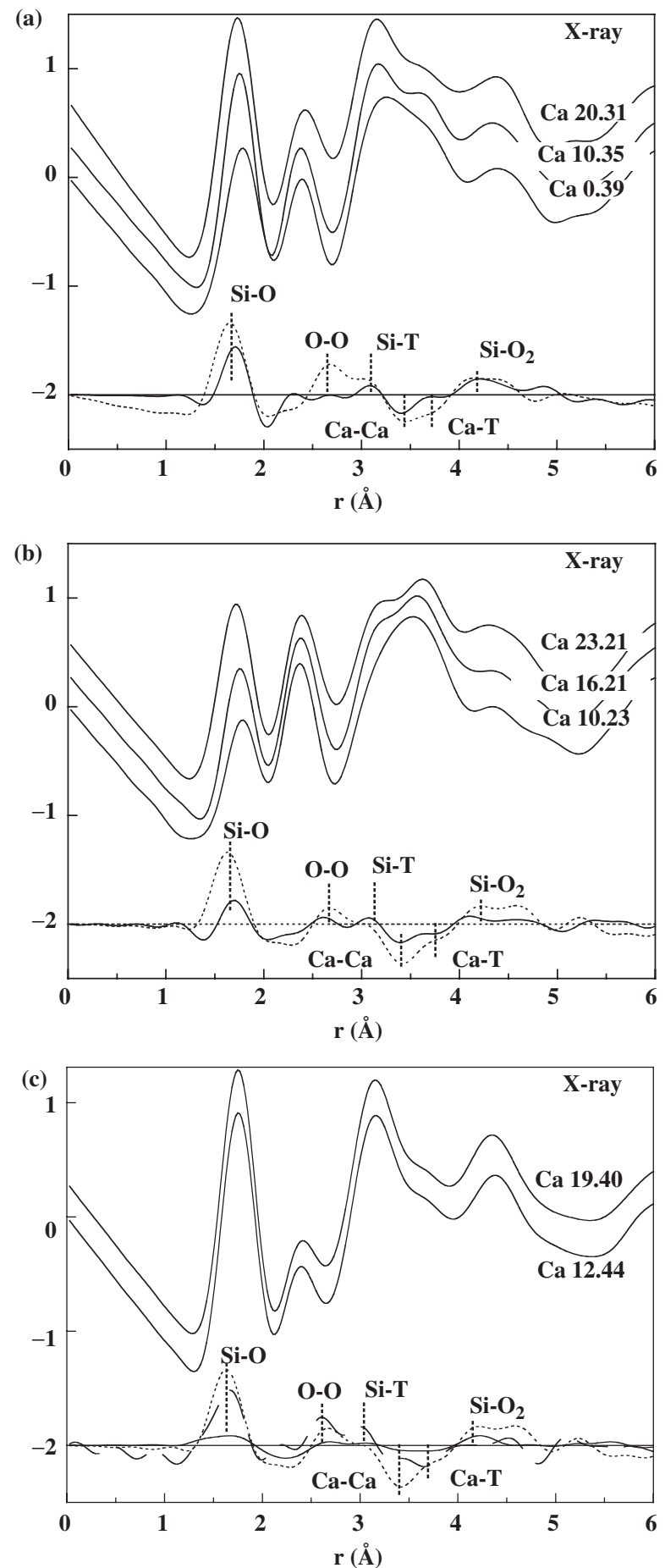

Fig. 7. Total and difference $\mathrm{X}$-ray correlation functions (top curves) at almost constant $\mathrm{Al}_{2} \mathrm{O}_{3}$ content along the join (a) $R=1.57$, (b) $R=3$, and (c) $R=1$. X-ray difference functions (bottom curves) are taken between (a) $\mathrm{Ca} 0.39-\mathrm{Ca} 10.35$ (plain curve) and $\mathrm{Ca} 0.39-\mathrm{Ca} 20.31$ (dashed curve), (b) Ca10.23-Ca16.21 (plain curve) and Ca10.23-Ca23.21 (dashed curve), (c) Ca12.44-Ca19.40 (solid line) compared with the differences between Ca10.35-Ca20.31 (crosses), and Ca10.23-Ca23.21 (dots).
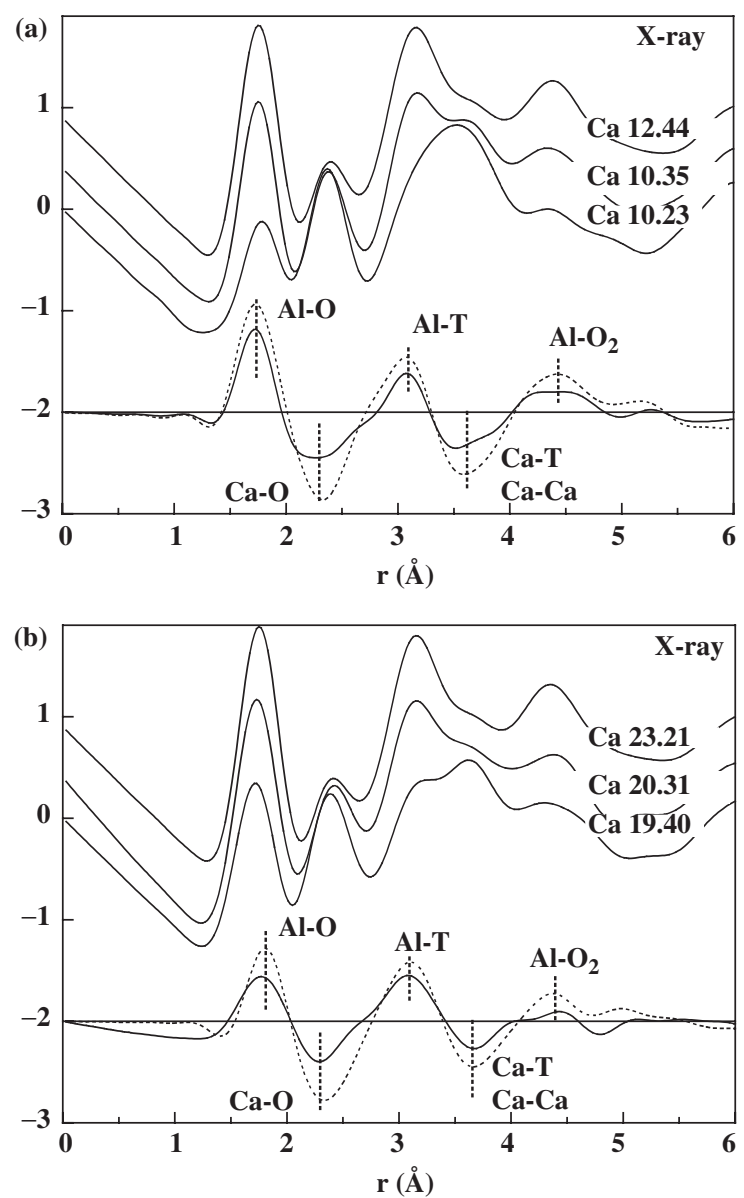

Fig. 8. Total and difference $\mathrm{X}$-ray correlation functions (top curves) at constant $\mathrm{SiO}_{2}$ content of (a) 10 and (b) $20 \mathrm{~mol} \%$. X-ray difference functions (bottom curves) are taken between (a) Ca10.23-Ca10.35 (plain curve) and Ca10.23-Ca12.44 (dashed curve), (b) Ca23.21-Ca20.31 (long dashed curve) and Ca23.21-Ca19.40 (dashed curve).

X-ray correlation difference functions were calculated for compositions with similar contents of $\mathrm{Al}_{2} \mathrm{O}_{3}$ (Fig. 7) and $\mathrm{SiO}_{2}$ (Fig. 8). By making the reasonable hypothesis that there are few changes for the $\mathrm{Al}-\mathrm{O}$ and $\mathrm{Al}-\mathrm{Al}$ pairs between glasses at constant $\mathrm{Al}_{2} \mathrm{O}_{3}$ content, the difference functions should eliminate most of the $\mathrm{Al}-\mathrm{O}$ and $\mathrm{Al}-\mathrm{Al}$ PPDFs. Therefore, in the X-ray difference functions, the peak near $3 \AA$ can be assigned to $\mathrm{Si}-\mathrm{T}$ correlations only (the $\mathrm{Al}-\mathrm{Al}$ signal is removed by the subtraction of the $G(r)$ functions). The feature at $4.2 \AA$ can be attributed to $\mathrm{Si}-\mathrm{O} 2$ pairs, since the $\mathrm{Al}-\mathrm{O} 2$ contribution near $4.2 \AA$ is cancelled during the subtraction. Similarly, Figure 8 shows the X-ray difference functions obtained at constant $\mathrm{SiO}_{2}$ content (10 and 20 $\mathrm{mol} \%$ ). In these difference functions, the $\mathrm{Si}-\mathrm{O}$ and $\mathrm{Si}-\mathrm{Si}$ PPDFs are removed and the peaks at 3.1 and $4.4 \AA$ can be attributed to $\mathrm{Al}-\mathrm{T}$ and $\mathrm{Al}-\mathrm{O} 2$ pairs, respectively.

With the addition of $\sim 10 \mathrm{~mol}_{0} \mathrm{Al}_{2} \mathrm{O}_{3}$, the Al-T contributions near $3.1 \AA$ (Fig. 8, lower curves) are markedly more important that the $\mathrm{Si}-\mathrm{T}$ contributions near $3.1 \AA$ when $\sim 10 \mathrm{~mol} \%$ $\mathrm{SiO}_{2}$ is added (Figs. 7(a) and (b), lower curves).

With the addition of $\mathrm{CaO}$, two peaks appear at about 3.4 and $3.7 \AA$ for the difference functions at constant $R$ while a unique contribution is visible at $3.7 \AA$ for the difference function at constant $\mathrm{SiO}_{2}$ content. The $\mathrm{Ca}-\mathrm{Ca}$ and $\mathrm{Ca}-\mathrm{T}$ pairs correspond to the peaks at 3.4 and $3.7 \AA$, respectively.

\section{Discussion}

(1) Local Environments in Calcium Aluminosilicate Glasses

The Gaussian fits of the neutron correlation functions (Table II) are consistent with the presence of $\mathrm{SiO}_{4}$ tetrahedra. The Gauss- 
ian parameters for the $\mathrm{Al}-\mathrm{O}$ pair indicate that $\mathrm{Al}$ occurs mainly in tetrahedral sites in all compositions. In the neutron correlation function, the $\mathrm{O}-\mathrm{O}$ peak is shifted from $2.88 \AA$ in the $\mathrm{Ca} 0.39$ glass to $2.77 \AA$ in the $\mathrm{Ca} 20.31$ glass. This shift is due to the shorter $\mathrm{O}-\mathrm{O}$ distances in $\mathrm{SiO}_{4}$ than in $\mathrm{AlO}_{4}$ tetrahedra (2.65 and $2.88 \AA$, respectively). The occurrence of $\mathrm{Al}$ in 4-fold coordination is in agreement with previous Raman and MAS-NMR studies, ${ }^{9,11,12,16}$ with a mean Al-O bond length of $1.76 \AA$. The symmetry of the Al-O peak in the silica-free sample, $\mathrm{Ca} 0.39$, rules out the possibility of a significant amount of $\mathrm{Al}$ in highcoordinated species. However, small amounts of high-coordinated species, which have been recently observed by high-field NMR, cannot be ruled out due to the precision of the diffraction data. ${ }^{28}$ The local environment of $\mathrm{Al}$ in aluminosilicate glasses is different to that observed in the corresponding liquids or rapidly quenched glasses, for which $\mathrm{Al}$ in 5- or 6-fold coordination has been reported by ${ }^{27} \mathrm{Al} \mathrm{NMR}$ and Molecular Dynamics calculations. ${ }^{29,30,11,12}$

An exact determination of the $\mathrm{Ca}$ site is difficult due to the proximity of the partly overlapping $\mathrm{O}-\mathrm{O}$ pairs. A coordination number of 5 and a mean $\mathrm{Ca}-\mathrm{O}$ distance of $2.35 \pm 0.01 \AA$ are in agreement with $\mathrm{Ca}$ in octahedral sites $\left(d_{\mathrm{Ca}-\mathrm{O}}=2.4 \AA\right)$. The low coordination number observed in these glasses can be due to a non-Gaussian distribution of the $\mathrm{Ca}-\mathrm{O}$ distances. This was indeed observed in the $\mathrm{CaSiO}_{3}$ glass, ${ }^{31}$ where neutron diffraction data on isotopically substituted samples allowed isolation of the first $\mathrm{Ca}-\mathrm{O}$ contribution. $\mathrm{Ca}-\mathrm{O}$ distances were found to be centered at $2.37 \AA$ with an additional broad distribution stretching from 2.5 to $2.85 \AA$. In our diffraction data, no modification of the local environment around $\mathrm{Ca}$ can be observed for the various studied glasses. An exact determination of the $\mathrm{Ca}$ sites is required to infer possible structural differences between a charge-compensating role or a modifying one, as observed for Sr using chemically selective techniques. ${ }^{32}$

\section{(2) Medium Range Structure of the Network}

For all glass compositions, the X-ray total correlation functions show a peak between 4.0 and $4.5 \AA$ that has been assigned to $\mathrm{T}-$ $\mathrm{O} 2$ and T-T2 components. ${ }^{17,27}$ The T-T2 distances falling in this range of values are characteristic of $\mathrm{T}-\mathrm{T}$ distances in fourmembered rings. The lack of contributions at $\sim 5.1 \AA$ confirms the small proportion of six-membered rings in the glass structure. There is thus evidence of a four-membered ring structure in calcium aluminosilicate glasses, which is in agreement with a previous X-ray diffraction study of an anorthite glass $\left(\mathrm{CaAl}_{2-}\right.$ $\left.\mathrm{Si}_{2} \mathrm{O}_{8}\right) \cdot{ }^{17} \mathrm{~A}$ determination of the average inter-tetrahedral angle, $\alpha=\mathrm{T}-\mathrm{O}-\mathrm{T}$, can be assessed from the average $\mathrm{T}-\mathrm{O} 1$ and $\mathrm{T}-\mathrm{T} 1$ distances, $\alpha=2 \sin ^{-1}(d(\mathrm{~T}-\mathrm{T} 1) / 2 d(\mathrm{~T}-\mathrm{O} 1))$. For the join $R=1$, the $\mathrm{T}-\mathrm{O} 1$ and $\mathrm{T}-\mathrm{T} 1$ distances are respectively $1.75 \pm 0.01$ and $3.15 \pm 0.01 \AA$, which give a $\mathrm{T}-\mathrm{O}-\mathrm{T}$ angle of $142.6^{\circ}$, in close agreement with the angle of $143^{\circ}$ determined for the anorthite glass. ${ }^{17}$ For the other joins, an exact determination of the T-T1 distance is not possible due to the overwhelming contribution of the $\mathrm{Ca}-\mathrm{Ca}$ pair. The decrease in the average $\mathrm{T}-\mathrm{O}-\mathrm{T}$ angle with increasing silica content is consistent with $a b$ initio Molecular Orbital calculation, which observed that increasing the average $\mathrm{T}-\mathrm{O}$ bond length reduces the $\mathrm{T}-\mathrm{O}-\mathrm{T}$ angle. ${ }^{33}$ However, the modifications of $\mathrm{T}-\mathrm{O}-\mathrm{T}$ angle with the composition do not present a relation with variations of $T_{\mathrm{g}}$, as confirmed by Molecular Dynamics calculations. ${ }^{34}$

The Ca environment is assessed by the two peaks at 3.4 and $3.7 \AA$ corresponding to $\mathrm{Ca}-\mathrm{Ca}$ and $\mathrm{Ca}-\mathrm{T}$ pairs, respectively, in the X-ray difference functions. The variations in the intensity of these peaks are more important for the glasses along the join $R=3$ than for glasses along the joins $R=1$ and 1.57. The change in the $\mathrm{CaO}$ content cannot be the only reason for the evolution of these peaks and structural modifications have to be taken into account. For glasses containing a high $\mathrm{CaO}$ content, we observe that $\mathrm{Al}$ enters preferentially in $\mathrm{Q}^{3}$ sites (see Section $\mathrm{IV}(3)$ ). This change in the polymerization state around $\mathrm{Al}$ yields a reorganization of the $\mathrm{Ca}$ atoms, which act, for these compo- sitions, both as charge compensator near $\mathrm{AlO}_{4}$ tetrahedra and as network modifier associated with the NBOs of the $\mathrm{Q}^{3}$ units. However, our data do not allow an estimate of the number of $\mathrm{Ca}$ or $\mathrm{T}$ nearest neighbors around a $\mathrm{Ca}$ atom.

Several authors have reported the presence of $\mathrm{O}_{2}^{-}$superoxide in the calcium aluminosilicate containing low silica content. ${ }^{5-8}$ From the diffraction data, no signature due to such species can be observed. This could mainly be observed in the $\mathrm{O}-\mathrm{O}$ peak near $2.6 \AA$. In the neutron data, which emphasize the $\mathrm{O}-\mathrm{O}$ correlation pair, the variation of the $\mathrm{O}-\mathrm{O}$ peak corresponds to the variation of the edges of the $\mathrm{AlO}_{4}$ and $\mathrm{SiO}_{4}$ tetrahedra during the $\mathrm{Si} / \mathrm{Al}$ substitution and it seems difficult to deconvolute from these contributions a distance characteristic of the peroxy linkages. Furthermore, a Molecular Dynamics study on the glasses with low silica content indicates the presence of $\sim 1 \%$ of oxygen present in $\mathrm{O}^{2-}$ form in the $\mathrm{Ca} 0.39$ glass, ${ }^{34}$ with a proportion decreasing as the silica content increases in agreement with experimental findings. ${ }^{5,7}$ The small content of $\mathrm{O}^{2-}$ in the simulated models suggests that the proportion of peroxy linkages should be very small in the glass and thereby undetectable with the diffraction methods.

\section{(3) Introduction of Si and Al in the Network}

The neutron difference functions (Fig. 6, lower curves) show a gradual increase in the $\mathrm{Si}-\mathrm{O} 2$ contribution at $4.2 \pm 0.02 \AA$. This $\mathrm{Si}-\mathrm{O} 2$ pair is related to the linkage of $\mathrm{a} \mathrm{SiO}_{4}$ tetrahedra with $\mathrm{SiO}_{4}$ or $\mathrm{AlO}_{4}$ tetrahedra. Such a linkage indicates that silicon is part of the aluminate network even at low silica content. The Xray difference functions (Figs. 7, lower curves) confirm that $\mathrm{Si}$ is part of the polymerized network at low silica content, with the presence of a peak at $3.1 \AA$ due to $\mathrm{Si}-\mathrm{T}$ pairs. The $\mathrm{Si}-\mathrm{O} 2$ contribution at $4.2 \mathrm{~A}$ is also discernible in spite of the lower quality of the X-ray data compared to the neutron ones. The lack of significant structural modifications with the addition of silica indicates that $\mathrm{Si}$ atoms do not play a major role in the observed thermodynamic anomaly. This result confirms a ${ }^{29} \mathrm{Si}$ NMR study that shows that the surrounding of the Si nuclei does not change rapidly at low silica content in contrast to large variations at high silica content. ${ }^{10}$

Based on their composition, glasses along the join $R=1$ are expected to have a fully connected network, with all $\mathrm{T}$ atoms in $\mathrm{Q}^{4}$ sites (where the superscript is the number of bridging oxygens, BOs, per tetrahedral cations). ${ }^{21}$ The X-ray difference functions for the Ca19.40 and Ca12.44 glasses (Fig. 7(c), lower plain curve) show very small structural oscillations compared to differences taken along the join $R=1.57$ and 3 for similar $\mathrm{SiO}_{2}$ content. This indicates that the addition of silica in the glasses along the join $R=1$ does not produce important modification within the glass structure. This lack of modification is consistent with a random $\mathrm{Si}$ to $\mathrm{Al}$ substitution in $\mathrm{Q}^{4}$ sites.

The difference functions, at constant $\mathrm{SiO}_{2}$ or $\mathrm{Al}_{2} \mathrm{O}_{3}$ content, allow the separation of the $\mathrm{Si}-\mathrm{T}$ and $\mathrm{Al}-\mathrm{T}$ contributions. Contrary to the weak $\mathrm{Si}-\mathrm{T}$ contribution, the Al-T contribution is characterized by a well-defined peak. This result indicates that Al enters the glass structure in tetrahedral sites with a large number of $\mathrm{T}$ neighbors and a narrow distribution of these neighbors. These criteria are fulfilled if $\mathrm{Al}$ preferentially enters $\mathrm{Q}^{4}$ sites as silica is added to aluminate compositions. In the difference functions at constant $\mathrm{Al}_{2} \mathrm{O}_{3}$ content (Fig. 7), the weak $\mathrm{Si}-\mathrm{T}$ contributions can be explained by $\mathrm{Si}$ atoms entering the glass framework in various $\mathrm{Q}^{n}$ sites (smaller number of T neighbors and larger distribution of $\mathrm{T}$ neighbors compared to $\mathrm{Al}$ ). Previous ${ }^{29} \mathrm{Si}$ and ${ }^{27} \mathrm{Al}$ MAS-NMR studies indicate that $\mathrm{Al}$ resides mostly in $\mathrm{Q}^{4}$ sites in aluminosilicate glasses and is increasingly found in $\mathrm{Q}^{3}$ sites in more lime compositions, ${ }^{9,15}$ which is in agreement with our X-ray diffraction data. However, these studies were unable to resolve quantitatively the $\mathrm{Q}^{n}$ peaks due to high-field strength cations, the increased number of next nearest neighbor configurations and the quadrupolar interactions in the case of $\mathrm{Al} .{ }^{9,10} \mathrm{~A}$ recent $\mathrm{Al} \mathrm{K}$-edge X-ray absorption spec- 
troscopic study also supports the present observation of a $\mathrm{Q}^{n}$ speciation of Al upon composition. ${ }^{14}$

The presence of $\mathrm{Al}$ in $\mathrm{Q}^{3}$ and $\mathrm{Q}^{4}$ sites in aluminate glasses is confirmed in the $12 \mathrm{CaO} \cdot 7 \mathrm{Al}_{2} \mathrm{O}_{3}(\mathrm{Ca} 0.37)$ glass that has a structure closer to the sheet framework of the $5 \mathrm{CaO} \cdot 3 \mathrm{Al}_{2} \mathrm{O}_{3}$ crystal than to the three-dimensional framework of the $12 \mathrm{CaO} \cdot 7 \mathrm{Al}_{2} \mathrm{O}_{3}$ crystal. ${ }^{18}$ Similarly, NMR, Raman, and infrared-reflectance spectroscopies ${ }^{15}$ have shown that $\mathrm{Al}$ is increasingly found in $\mathrm{Q}^{3}$ sites as $\mathrm{CaO}$ content increases. Hence, glass compositions with high $\mathrm{CaO}$ and low $\mathrm{SiO}_{2}$ content do favor sheet structures.

\section{(4) Glass Transition Temperature and Structure}

The glass transition is strongly associated with melts properties such as viscosity and shear modulus. ${ }^{35}$ The $T_{\mathrm{g}}$ value corresponds to a temperature region where the structure of the liquid is frozen on an experimental time scale. At higher temperature, there is a continual structural rearrangement through breaking and reforming of $\mathrm{T}-\mathrm{O}$ bonds. This relaxation process is associated with viscous flow in silica melts and has been attributed to the $\mathrm{O}^{2-}$ exchange between $\mathrm{Q}^{n}$ species, with the involvement of a fivecoordinated transient silicon site. ${ }^{36}$ In this mechanism, an NBO combines with a $\mathrm{SiO}_{4}$ tetrahedra to form short-lived $\mathrm{SiO}_{5}$ units. ${ }^{36}$ Therefore, the number of NBOs or the network polymerization may play an important role in the flow of melts. This effect is apparent in Fig. 2, where the fully compensated glasses along the join $R=1$ have the highest $T_{\mathrm{g}}$ values while the most depolymerized glasses along the join $R=3$ have the lowest $T_{\mathrm{g}}$ values. Therefore, the knowledge of the proportion of $\mathrm{Q}^{n}$ species in aluminosilicate melts is an important parameter for better understanding the chemical dependence of the macroscopic flow.

The structural information gained by the diffraction data may help in linking the glass structure to the variations of the glass transition temperatures $\left(T_{\mathrm{g}}\right)$. For glasses along the join $R=1$ and with $\mathrm{SiO}_{2}$ content above $12 \mathrm{~mol} \%$, no maximum in $T_{\mathrm{g}}$ is observed as silica is added contrary to the other joins (Fig. 2). This is in agreement with a random substitution of $\mathrm{Al}$ atoms by $\mathrm{Si}$ atoms in $\mathrm{Q}^{4}$ sites. In such a replacement, the connection of the network is not altered and we do not observe extrema in the $T_{\mathrm{g}}$ at low silica content. From the pure calcium aluminate network $\left(\mathrm{CaAl}_{2} \mathrm{O}_{4}\right)$, there is only a continuous decrease in the $T_{\mathrm{g}}$ with the adding of silica until $30 \mathrm{~mol} \% \mathrm{SiO}_{2}$. The introduction of $\mathrm{SiO}_{2}$ enhances the structural constraints on the network due to the $\mathrm{Si} / \mathrm{Al}$ disorder and the requirement to preserve a fully polymerized network. The decrease in $T_{\mathrm{g}}$ can thus be simply related to the mixing of the network formers. ${ }^{22}$ Indeed, $\mathrm{Al}-\mathrm{O}$ bonds are weaker than $\mathrm{Si}-\mathrm{O}$ bonds and more likely to be broken during the $\mathrm{O}$ exchange, which is proposed to be responsible for the macroscopic flow. ${ }^{36}$

At low silica content, the network is mainly based on the $\mathrm{AlO}_{4}$ tetrahedra, with dispersed $\mathrm{SiO}_{4}$ units. With increasing content of $\mathrm{CaO}$ (joins $R=1.57,3$ ), the structure of glasses containing low silica content becomes more sheet like with an increasing number of $\mathrm{Al}$ in $\mathrm{Q}^{3}$ positions. The connectivity of the network decreases and then less thermal energy is required for movements at high temperature. This explains why the melts are less viscous, which implies that the $T_{\mathrm{g}}$ values are lower for these glasses than those along the join $R=1$. This effect becomes more important as the $\mathrm{CaO}$ content increases, suggesting that the network becomes even more depolymerized for the CaO-rich glasses (join $R=3$ ). With the addition of silica, $\mathrm{Si}$ is preferentially localized in various depolymerized $\mathrm{Q}^{n}$ species and, conversely, the number of $\mathrm{Al}$ in $\mathrm{Q}^{4}$ sites increases. The aluminate network thus becomes more connected, which increases $T_{\mathrm{g}}$. After the maximum observed in the $T_{\mathrm{g}}$ values, the distribution of $\mathrm{Si}$ and $\mathrm{Al}$ over $\mathrm{Q}^{n}$ species is more homogeneous and $\mathrm{Si}$ contributes to the polymerization of the network. Therefore, the simple $\mathrm{Si} / \mathrm{Al}$ mixing may again explain the decrease in $T_{\mathrm{g}}$ above $10-20 \mathrm{~mol}_{0} \mathrm{SiO}_{2}$.

The structure of the glasses corresponds to a frozen structure of the liquid state depending on the quenching rate. A previous study on calcium aluminate glasses has shown that the structural differences due to different quenching rates do not affect the aluminate polymerization state ${ }^{37} \mathrm{~A}$ rearrangement of the $\mathrm{Ca}$ atoms surrounding the Al site was instead proposed. With the present diffraction data, it is not possible to determine quantitatively the $\mathrm{Ca}-\mathrm{Al}$ distribution. We can note that the lack of polymerization change for glasses prepared with different quenching rates indicates that the diffraction results obtained on the glass polymerization are characteristics of the liquid state. Glasses with low silica content are known to correspond to fragile liquids and, thus, configurational changes above $T_{\mathrm{g}}$ are expected to occur. In calcium aluminate glasses, high-temperature Raman spectroscopy have shown only vibrational (anharmonic) changes ${ }^{37}$ while NMR data have indicated the presence of $\mathrm{AlO}_{5}$ species at very high temperature. ${ }^{29}$ This highly coordinated Al species may play a role in oxygen diffusion and the viscous flow process in the liquids. Diffraction measurements at high temperature should give more complement information on the configurational changes above $T_{\mathrm{g}}$.

\section{Conclusions}

The glass transition temperature presents a striking maximum at low silica content $(<20 \mathrm{~mol} \%)$, in calcium aluminosilicate glasses for the joins $R=\mathrm{CaO} / \mathrm{Al}_{2} \mathrm{O}_{3}=1.57$ and 3 contrary to the join $R=1$. X-ray and neutron diffraction techniques have been used to study the structure of these glasses. The diffraction data indicate that the network is based on $\mathrm{SiO}_{4}$ and $\mathrm{AlO}_{4}$ tetrahedra and that $\mathrm{Ca}$ atoms are in octahedral sites providing charge compensation near Al. With the addition of silica, there are continuous structural modifications and, in particular, we do not see evidence of abrupt structural changes for the glass having the highest $T_{\mathrm{g}}$. The variations in properties of these glasses with the addition of silica are not due to changes in the environment around $\mathrm{Si}$ atoms. We have shown that $\mathrm{Si}$ and $\mathrm{Al}$ atoms are introduced in a different way into the glass structure. Al is usually found in fully polymerized $\mathrm{Q}^{4}$ sites, even in depolymerized aluminosilicate glasses. However, for glasses with high $\mathrm{CaO}$ content and low $\mathrm{SiO}_{2}$ content, $\mathrm{Al}$ resides in $\mathrm{Q}^{3}$ as well as $\mathrm{Q}^{4}$ sites, while $\mathrm{Si}$ is distributed over several depolymerized $\mathrm{Q}^{n}$ positions. The proportion of $\mathrm{Al}$ in $\mathrm{Q}^{3}$ positions increases with $\mathrm{CaO}$, which implies a rapid decrease in the viscosity and in the glass transition temperature for low silica glasses.

\section{Acknowledgments}

The authors are grateful for the constructive comments of two anonymous reviewers. This is IPGP contribution no. 1898.

\section{References}

${ }^{1}$ G. A. Rankin, "The Ternary System $\mathrm{CaO}-\mathrm{Al}_{2} \mathrm{O}_{3}-\mathrm{SiO}_{2}$," Am. J. Sci., 39, 1-79 (1915)

${ }^{2}$ G. A. Rankin and F. E . E Wright, "The Ternary System $\mathrm{CaO}-\mathrm{Al}_{2} \mathrm{O}_{3}-\mathrm{SiO}_{2}$," Am. J. Sci., 39, 1-79 (1915).

${ }^{3}$ J. E. Shelby, "Formation and Properties of Calcium Aluminosilicate Glasses," J. Am. Ceram. Soc., 68, 155-58 (1985).

${ }^{4}$ P. L. Highby, R. J. Ginther, I. D. Aggarwal, and E. J. Friebele, "Glass Formation and Thermal Properties of Low-silica Calcium Aluminosilicate Glasses," J. Non-Cryst. Solids, 126, 209-15 (1990).

${ }^{5}$ D. A. Dutt, P. L. Highby, and D. L. Griscom, "A Structural Model for Low Silica Content Calcium Aluminosilicate Glasses," Phys. Chem. Glasses, 33, 51-55 (1992).

${ }^{6} \mathrm{H}$. Hosono and Y. Abe, "An Oxygen-effervescent Aluminate Glass," J. Am. Ceram. Soc., 70, C38-C39 (1987).

${ }^{7}$ D. A. Dutt, P. L. Highby, and D. L. Griscom, “An Electron Spin Resonance Study of X-irradiated Calcium Aluminosilicate Glasses," J. Non-Cryst. Solids, 130, 41-51 (1991).

${ }^{8}$ M. C. Badets, B. Coté, P. Simon, and J.-P. Coutures, "E.P.R. Study of the Oxygen Effect on the $\mathrm{CaO}-\mathrm{Al}_{2} \mathrm{O}_{3}-\mathrm{SiO}_{2}$ Glasses Elaborated Under Contactless Conditions," Ann. Chim. Fr., 15, 455-61 (1990).

${ }^{9}$ C. I. Merzbacher, B. L. Sheriff, J. S. Hartman, and W. B. White, "A Highresolution ${ }^{29} \mathrm{Si}$ and ${ }^{27} \mathrm{Al}$ NMR Study of Alkaline Earth Aluminosilicate Glasses," J. Non-Cryst. Solids, 124, 194-206 (1990).

${ }^{10}$ C. I. Merzbacher, K. J. McGrath, and P. L. Highby, “29 Si NMR and Infrared Reflectance Spectroscopy of Low-silica Calcium Aluminosilicate Glasses," J. NonCryst. Solids, 136, 249-59 (1991).

${ }^{11}$ B. Coté, D. Massiot, F. Taulelle, and J.-P. Coutures, “'27 Al NMR Spectroscopy of Aluminosilicate Melts and Glasses," Chem. Geol., 96, 367-70 (1992). 
${ }^{12}$ B. Coté, D. Massiot, B. Poe, P. McMillan, F. Taulelle, and J -P. Coutures, "Liquids and Glasses Structural Differences in the $\mathrm{CaO}-\mathrm{Al}_{2} \mathrm{O}_{3}$ system, as Evidenced by ${ }^{27}$ Al NMR Spectroscopy," J. Phys. IV, 2, C2-223-C2-26 (1992).

${ }^{13}$ C. Landron, B. Coté, D. Massiot, J.-P. Coutures, and A.-M. Flanck, “Aluminium XAS and NMR Spectroscopic Studies of Calcium Aluminosilicate Glasses," Phys. Stat. Sol, b171, 9-20 (1992).

${ }^{14}$ D. R. Neuville, L. Cormier, A.-M. Flank, V. Briois, and D. Massiot, "Al speciation and $\mathrm{Ca}$ Environment in Calcium Aluminosilicate Glasses and Crystals by Al and Ca K-edge X-ray Absorption Spectroscopy," Chem. Geol., 213, 153-163 (2004).

${ }^{15}$ C. I. Merzbacher and W. B. White, "The Structure of Alkaline Earth Aluminosilicate Glasses as Determined by Vibrational Spectroscopy," J. Non-Cryst. Solids, 130, 18-34 (1991).

${ }^{16} \mathrm{P}$. McMillan and B. Piriou, "Raman Spectroscopy of Calcium Aluminate Glasses and Crystals," J. Non-Cryst. Solids, 55, 221-42 (1983).

${ }^{17}$ M. Taylor and G. E. Jr. Brown, "Structure of Mineral Glasses-I. The Feldspar Glasses $\mathrm{NaAlSi}_{3} \mathrm{O}_{8}, \mathrm{KAlSi}_{3} \mathrm{O}_{8}, \mathrm{CaAlSi}_{3} \mathrm{O}_{8}$, , Geochim. Cosmochim. Acta, 43, 61-75 (1979).

${ }^{18}$ H. Morikawa, F. Marumo, T. Koyama, M. Yamane, and A. Oyobe, "Structural Analysis of $12 \mathrm{CaO} \cdot 7 \mathrm{Al}_{2} \mathrm{O}_{3}$ Glass," J. Non-Cryst. Solids, 56, 355-60 (1983).

${ }^{19}$ A. C. Hannon and J. M. Parker, "The Structure of Aluminate Glasses by Neutron Diffraction," J. Non-Cryst. Solids, 274, 102-109 (2000).

${ }^{20}$ L. Cormier, D. R. Neuville, and G. Calas, "Structure and Properties of Lowsilica Calcium Aluminosilicate Glasses," J. Non-Cryst. Solids, 274, 110-14 (2000).

${ }^{21}$ B. O. Mysen, Structure and Properties of Silicate Melts. Elsevier, Amsterdam, 1988.

${ }^{22}$ D. R. Neuville "Etudes des propriétés thermodynamiques et rhéologiques des silicates fondus," Ph.D. Thesis, Université Paris VII. 1992.

${ }^{23}$ F. Farges, D. R. Neuville, and G. E. Jr. Brown, "Structural Investigation of Platinum Solubility in Silicate Glasses," Am. Minerol., 84, 1562-68 (1999).

${ }^{24} \mathrm{D}$. R. Neuville and P. Richet, "Viscosity and Mixing in Molten (Ca, Mg) Pyroxene Garnets," Geochim. Cosmochim. Acta, 55, 1011-19 (1991).

${ }^{25}$ L. Cormier, D. Ghaleb, J.-M. Delaye, and G. Calas, "Competition for Charge Compensation in Borosilicate Glasses: Wide Angle X-ray Scattering and Molecular Dynamics Calculations," Phys. Rev. B, 61, 14495-99 (2000).
${ }^{26}$ A. K. Soper, W. S. Howells, and A. C. Hannon, Rutherford Appleton Laboratory Report, RAL-89-046, 1989.

${ }^{27}$ N. Zotov, H. Boysen, C. Romano, D. Dingwell, and Y. Yanev, "Neutron Diffraction Study of Feldspar Glasses. mixed Alkali Effect," J. Non-Cryst. Solids, 1191, 124-31 (1995).

${ }^{28}$ D. R. Neuville, L. Cormier, and D. Massiot, “Al Environment in Tectosilicate and Peraluminous Glasses: a ${ }^{27} \mathrm{Al}$ MQ-MAS NMR, Raman, and EXAFS Investigation," Geochim. Cosmochim. Acta, 68, 5071-5079 (2004).

${ }^{29}$ B. T. Poe, P. F. McMillan, B. Coté, D. Massiot, and J.-P. Coutures, "Magnesium and Calcium Aluminate Liquids: In Situ High Temperature ${ }^{27}$ Al NMR Spectroscopy,' Science, 259, 786-88 (1993).

${ }^{30}$ B. T. Poe, P. F. McMillan, B. Coté, D. Massiot, and J.-P. Coutures, "Structure and Dynamics in Calcium Aluminate Liquids: High-Temperature ${ }^{27}$ Al NMR and Raman Spectroscopy," J. Am. Ceram. Soc., 77, 1832-38 (1994).

${ }^{31}$ P. H. Gaskell, M. C. Eckersley, A. C. Barnes, and P. Chieux, "Medium-Range Order in the Cation Distribution of a Calcium Silicate Glass," Nature, 350, 675-77 (1991).

${ }^{32}$ L. Cormier, G. Calas, S. Creux, P. H. Gaskell, B. Bouchet-Fabre, and A. C. Hannon, "Environment Around Strontium in Silicate and Aluminosilicate Glasses," Phys. Rev. B, 59, 13517-20 (1999).

${ }^{33}$ K. L. Geisinger, G. V. Gibbs, and A. Navrotsky, "A Molecular Orbital Study of Bond Length and Angle Variations in Framework Structures," Phys. Chem. Minerals, 11, 266 (1985).

${ }^{34}$ L. Cormier, D. Ghaleb, D. R. Neuville, J.-M. Delaye, and G. Calas, "Chemical Dependence of Network Topology of Calcium Aluminosilicate Glasses: A Molecular Dynamics and Reverse Monte Carlo study," J. Non-Cryst. Solids, 332, 255-270 (2003).

${ }^{35}$ C. A. Angell, "Perspective on the Glass Transition," J. Phys. Chem. Solids, 49, 863-71 (1988).

${ }^{36}$ I. Farnan and J. F. Stebbins, "The Nature of the Glass Transition in a SilicaRich Oxide Melt," Science, 265, 1206-08 (1994).

${ }^{37}$ P. F. McMillan, W. T. Petuskey, B. Coté, D. Massiot, C. Landron, and J.-P. Coutures, "A Structural Investigation of $\mathrm{CaO}-\mathrm{Al}_{2} \mathrm{O}_{3}$ Glasses via ${ }^{27} \mathrm{Al}$ MASNMR,” J. Non-Cryst. Solids, 195, 261-71 (1996). 